\title{
Malignant transformation of anal skin tags in Crohn's disease
}

\author{
K W SOMERVILLE, M J S LANGMAN, D J DA CRUZ, \\ T W BALFOUR, AND L SULLY \\ From the Departments of Therapeutics and Surgery, City Hospital, Nottingham
}

SUMmARY The anal skin tags of a young man with ileal and perianal Crohn's disease underwent malignant transformation. This was not associated with immunosuppressive drug therapy and has not been previously described.

An increased risk of intestinal cancer has been reported in Crohn's disease although the relative risk is not as high as for colonic carcinoma in ulcerative colitis. We report a young patient with Crohn's disease whose anal skin tags underwent malignant change.

\section{Case report}

A 26 year old white heterosexual man was investigated in 1978 because of rectal bleeding and anaemia. At that time he had prominent anal skin tags, and although colonoscopy to the splenic flexure was unremarkable, a barium enema with ileal reflux showed narrowing and irregularity of the terminal ileium consistent with Crohn's disease. A small bowel radiograph showed a similar appearance: the remainder of the midgut was normal.

He was treated with sulphasalazine $2 \mathrm{~g}$ daily and, apart from a further episode of probable rectal bleeding in 1980, remained well. In June 1982, however, at a sideshow he fell out of a 'moon buggy' fracturing his left scaphoid and injuring his perineum. Subsequently his most prominent anal tag became painful and began to increase in size. He was readmitted in August because of heavy rectal bleeding and required transfusion. By then the tender and indurated perineal mass was $10 \times 7 \mathrm{~cm}$ with a small sinus draining anteriorly $2 \mathrm{~cm}$ away (Fig. 1). The anus was not involved.

Address for correspondence: Dr K W Somerville, Department of Therapeutics Floor C, South Block, University Hospital, Nottingham NG7 2UH.

Received for publication 9 December 1983

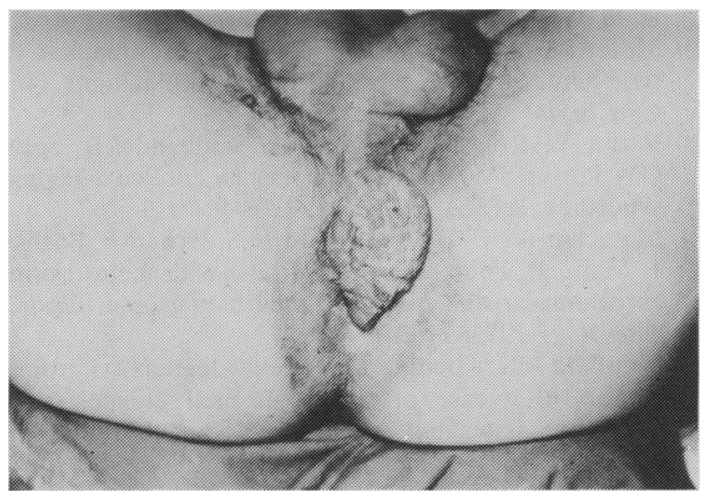

Fig. 1 Perineal tumour before resection.

A limited right hemicolectomy for the ileal disease was undertaken; the gross specimen and histology were consistent with Crohn's disease with thickening and deep ulceration of the ileal wall. No other intra-abdominal pathology was found. Biopsy of the perianal tumour confirmed a squamous cell carcinoma which was later widely excised preserving the anal sphincter. Repair was achieved with a split skin graft (Fig. 2). Nine months later he was well and there was no local tumour recurrence.

Because of the possibility that the malignancy was associated with an immune deficiency state, his immune status was investigated. His white count and differential, $\mathrm{T}$ and $\mathrm{B}$ lymphocyte numbers, $\mathrm{C}_{3}$ and $\mathrm{C}_{4}, \mathrm{C}$ reactive protein, serum immunoglobulins and autoantibody screens were normal. Syphillis serology (VDRL) was negative. 


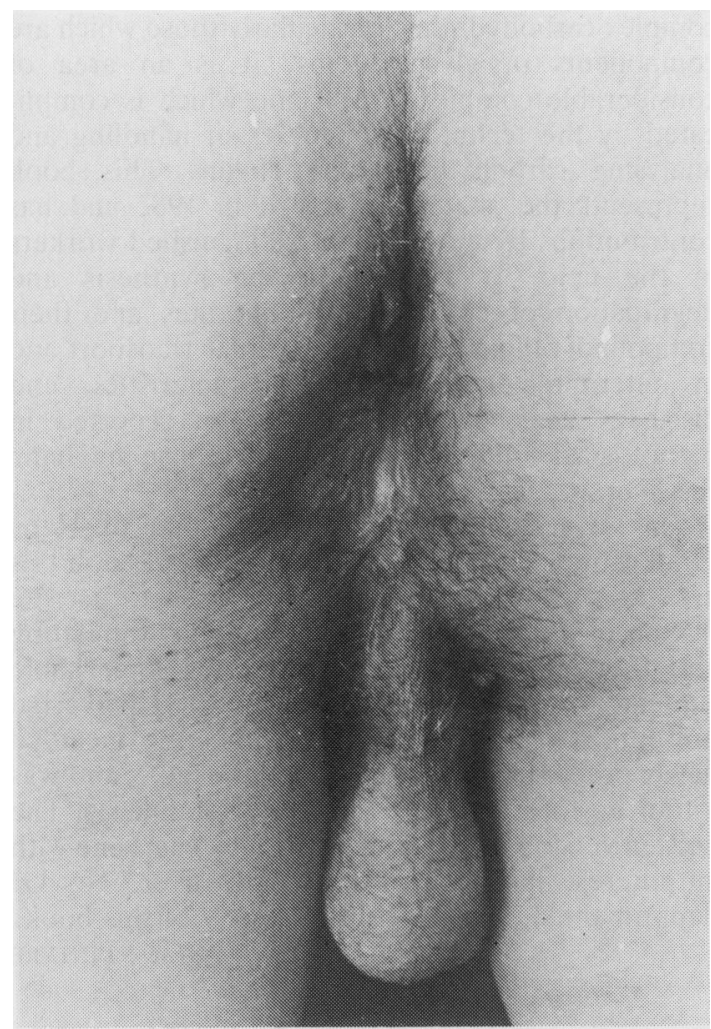

\section{Discussion}

The increased prevalence of bowel cancer in Crohn's disease is well documented. ${ }^{12}$ For example, in the Birmingham series ${ }^{1}$ there was an excess of tumours of both the upper and lower gastrointestinal tract. Of the 18 cases concerned, however, only one occurred in the anal region and this was an adenocarcinoma within the canal itself. We know of no previous report of malignant transformation of anal skin tags in Crohn's disease.

Why did this young man develop a squamous cell carcinoma at this site? The increase in size began after trauma, but this may be coincidental. There is a theoretical but unproven risk that immunosuppressive drugs often used in Crohn's disease such as azathioprine might increase the risk of cutaneous malignancy, ${ }^{3}$ but our patient had not received such agents and his peripheral blood immune status was intact. The association between Crohn's disease and malignancy is probably causal if only because the anal tags are a consequence of the inflammatory bowel disease itself.

\section{References}

1 Gyde SN, Prior P, Macartney JC, et al. Malignancy in Crohn's disease. Gut 1980; 21:1024-9.

2 Greenskin AJ, Sachar DB, Smith H, et al. Patterns of neoplasia in Crohn's disease and ulcerative colitis. Cancer 1980; 46: 403-7.

3 Kinlen LJ, Sheil AGR, Peto J, Doll R. Collaborative United Kingdom-Australasian study of cancer in

Fig. 2 Perineal region after removal of tumour and application of a split skin graft. 